throughout the country. The program's four levels of federal review provide a powerful shield against large numbers of cases reaching state courts. In any cases that do reach state courts, it is highly unlikely that plaintiffs will succeed without additional scientific advancements to support their claims. Because state courts must deliver judgments based on credible evidence that satisfies traditional legal standards, claims relying on evidence similar to that presented under the Omnibus Autism Proceeding will have difficulty surviving judicial scrutiny.

The government is committed to ensuring that the vaccine supply is as safe as the current state of scientific knowledge allows. This commitment includes oversight of all aspects of vaccine development, manufacturing, and administration and promotion of activities that ensure that adverse events are infrequent. As part of this obligation, the VICP has perhaps the saddest duty - determining which persons have truly been harmed by vaccines. Consequently, the program has adjudicated more than 7000 cases since its inception, yet only 2284 claims have been deemed legally eligible for awards, totaling $\$ 1.8$ billion. As Camp-
bell-Smith noted in Hazlehurst, the special master's charge "does not permit decision making on the basis of sentiment but rather requires a careful legal analysis of the evidence."3

No potential conflict of interest relevant to this article was reported.

Ms. Stewart is an assistant research professor at the Department of Health Policy, School of Public Health and Health Services, the George Washington University Medical Center, Washington, DC

1. Snyder v. Secretary of Health and Human Services, Case No. 01-162V.

2. Cedillo v. Secretary of Health and Human Services, Case No. 98-916V.

3. Hazlehurst v. Secretary of Health and Human Services, Case No. 03-654V.

Copyright (๑) 2009 Massachusetts Medical Society.

\title{
Litigation, Regulation, and Education - Protecting the Public's Health through Childhood Immunization
}

Ross D. Silverman, J.D., M.P.H.

D ecently, three special masters of the U.S. Court of Federal Claims issued carefully reasoned, strongly worded opinions rejecting claims that medical and scientific evidence could demonstrate causal links between thimerosal-containing vaccines or measles-mumps-rubella (MMR) vaccination and the development of chronic health conditions such as autism, immune dysfunction, and gastrointestinal dysfunction. The three cases were test cases drawn from more than 5000 similar claims filed under the National Vaccine Injury Compensation Program (VICP), which was established in 1988 in response to concerns that injury lawsuits against vaccine manufacturers and administrators were threatening the nation's childhood-vaccine supply. Because the injuries claimed in these cases were not listed in the VICP's Vaccine Injury Table, in order to receive compensation un- der the program, the families had to demonstrate through medical or scientific evidence that it is more likely than not that vaccination played a significant role in causing such injuries.

In VICP-related proceedings, the court has broad authority to seek out and consider information that might help it resolve questions about injury causation. Toward this end, the special masters informed their decisions by reviewing an extraordinary amount of scientific and medical evidence, including the testimony of 28 medical experts, 50 expert reports, and more than 5000 pages of proceedings transcripts and briefs that included more than 900 scientific articles.

The concern the special masters felt for the families who must cope with the daily challenges of caring for children with devastating chronic illnesses of as yet unknown origin is evident throughout the more than 600 pages of legal decisions. Furthermore, the special masters were convinced that the parents had filed their claims in good faith. However, they were far less sympathetic toward both the evidence proffered by the claimants and the physicians who testified and offered research in support of the claims. According to Special Master George Hastings, writing in Cedillo v. Sec'y of HHS, "This case ... is not a close case. The overall weight of the evidence is overwhelmingly contrary to the petitioners' causation theories. . . . Unfortunately, the Cedillos have been misled by physicians who are guilty, in my view, of gross medical misjudgment" (emphasis in the original). ${ }^{1}$ Absent significant and dramatic new scientific findings, future litigation attempting to tie autism to vaccination is likely to meet a similar fate. However, many challenges for the 
U.S. childhood immunization program remain to be addressed.

The success of the childhood immunization program can in part be traced to state laws requiring parents to provide evidence that their children have been vaccinated as a prerequisite for enrollment in schools and day-care centers. Although state authority to implement childhood immunization mandates is anchored in fundamental constitutional principles, states' processes for structuring the childhood vaccination program are highly politicized. States attempt to strike some balance between the power to require vaccination and consideration for parental beliefs and autonomy by allowing for exemptions from vaccine requirements. Most states permit exemptions on religious grounds, and a growing number of states permit exemption claims based on broader philosophical or personal objections. States also have widely varied administrative structures for approving exemption requests. Not surprisingly, states with expansive bases for exemption and more limited administrative requirements for fulfilling exemption requests have more parents opting out of vaccinating their children - a trend that increases the likelihood of outbreaks of vaccine-preventable diseases ${ }^{2}$ and creates potential geographic "hot spots" where high concentrations of exempted children may compromise community-wide protection. While continuing to support the rights of parents to choose to refuse vaccinations for their children, states should explore strengthening their administrative process for approving exemptions to ensure that they are limited to families with deeply held beliefs.

The benefits of vaccination to the child and the public are widely known and may be demonstrated with the use of scientific data. But parents weigh choices about vaccination using conceptions of risk, benefit, and trust that are broader than anything that can be demonstrated through statistics or biology. ${ }^{3}$ Trust can be enhanced by improving the transparency of the decision-making process for approving and enforcing vaccination mandates. A failure to ensure adequate public participation in this process can lead to a potentially damaging backlash against such public health interventions, as was seen in the extremely negative response to the decision by the governor of Texas to circumvent the legislature and issue an executive order mandating the vaccination of adolescent girls against the human papillomavirus (HPV), as well as the reaction to the news that the HPV vaccine manufacturer was lobbying hard to get the shot added to the list of mandatory immunizations. ${ }^{4}$ To minimize the chances of such backlashes, I would also argue that public health officials should explore options in lieu of mandates to encourage the uptake of new vaccinations, such as public education campaigns or public funding for immunization, and as others have, I would encourage states to consider limiting mandates to illnesses that can reasonably be tied to school attendance. ${ }^{5}$

Finally, and most important, for our childhood immunization program to continue to be successful, our health care system must offer greater support for primary care physicians who serve as educators for patients and advocates for patient participation in sound preventive care strategies. Although the Internet and the media offer unprecedented opportunities for the public to become informed (or potentially misinformed) about health-related topics, parents' understanding of such matters should be fostered primarily through dialogue that they have with their children's physicians as partners in care. Yet the U.S. reimbursement system for physicians undervalues the time and effort that doctors spend in this ca- pacity. As a result, physicians and parents may feel pressured to forgo the opportunity to explore the complex medical, scientific, psychological, emotional, and political issues raised by childhood immunization, and parents may remain skeptical about committing to vaccination if they leave the office feeling that the physician did not take (or have) the time to understand their concerns. Such impressions and attitudes may then be passed along to the children themselves - a dynamic that raises concerns about the potential effect of continued parental distrust on future public health-related decisions made by those children. As national health care reform efforts move forward, policymakers should be encouraged to support the restructuring of the reimbursement system in order to enhance the opportunity for physicians to engage in preventive care interventions, including efforts to educate patients and vaccine distribution.

Mr. Silverman reports receiving grant support from the American Medical Association and the Illinois Department of Public Health. No other potential conflict of interest relevant to this article was reported.

Mr. Silverman is a professor and chair of the Department of Medical Humanities and a professor of psychiatry at Southern Illinois University School of Medicine, Springfield, and a professor of medical jurisprudence at Southern Illinois University School of Law, Carbondale.

1. Cedillo v. Sec'y of HHS, U.S. Court of Fed. Claims, No. 89-916V (Filed February 12, 2009) at 172-173.

2. Omer SB, Pan WK, Halsey NA, et al. Nonmedical exemptions to school immunization requirements: secular trends and association of state policies with pertussis incidence. JAMA 2006; 296:1757-63.

3. Casiday RE. Children's health and the social theory of risk: insights from the British measles, mumps and rubella (MMR) controversy. Soc Sci Med 2007;65:1059-70.

4. Blumenthal R. Texas legislators block shots for girls against cancer virus. New York Times. April 26, 2007:A16.

5. Opel DJ, Diekema DS, Marcuse EK. A critique of criteria for evaluating vaccines for inclusion in mandatory school immunization programs. Pediatrics 2008;122(2):e504-e510.

Copyright (@) 2009 Massachusetts Medical Society. 